\title{
Macrophage migration inhibitory factor involvement in breast cancer (Review)
}

\author{
VINCENT RICHARD $^{1,2}$, NADĖGE KINDT ${ }^{1}$ and SVEN SAUSSEZ ${ }^{1,3}$ \\ ${ }^{1}$ Laboratory of Anatomy and Cell Biology, Faculty of Medicine and Pharmacy, University of Mons, B-7000 Mons; \\ ${ }^{2}$ Department of Medical Oncology, CHU Ambroise Paré, B-7000 Mons; ${ }^{3}$ Department of Oto-Rhino-Laryngology, \\ Faculty of Medicine, Free University of Brussels (ULB), CHU St-Pierre, B-1000 Brussels, Belgium
}

Received June 5, 2015; Accepted August 6, 2015

DOI: $10.3892 /$ ijo.2015.3185

\begin{abstract}
Macrophage migration inhibitory factor (MIF) is a pleiotropic inflammatory cytokine involved in many cellular processes and in particular carcinogenesis. Here, we review the experimental and clinical published data on MIF and its pathways in breast cancer. Experimental data show that MIF is overexpressed in breast cancer cells (BCC) due, at least partly, to its stabilization by HSP90 and upregulation by HIF-1 $\alpha$. MIF interacts with its main receptor CD74 and its co-receptor CXCR-4, both overexpressed, promoting cell survival by PI3K/Akt activation, a possible link with EGFR and HER2 pathways and inhibition of autophagy. Besides these auto- and paracrine effects on BCC, MIF interacts with BCC microenvironment by several mechanisms: immunomodulation by increasing the prevalence of immune suppressive cells, neo-angiogenesis by its link to HIF-1, and finally BCC transendothelial migration. Clinical studies show higher levels of MIF in breast cancer patients serum compared to healthy volunteers but without obvious clinical significance. In breast cancer tissue, MIF and CD74 are overexpressed in the cancer cells and in the stroma but correlations with classical prognostic factors or survival are elusive. However, an inverse correlation with the tumor size for stromal MIF and a positive correlation with the triple receptor negative tumor status for stromal CD74 seem to be showed. This set of experimental and clinical data shows the involvement of MIF pathways in breast carcinogenesis. Several anti-MIF targeted strategies are being explored in therapeutic goals and should merit further investigations.
\end{abstract}

Correspondence to: Dr Sven Saussez, Laboratory of Anatomy and Cell Biology, Faculty of Medicine and Pharmacy, University of Mons, B-7000 Mons, Belgium

E-mail: sven.saussez@umons.ac.be

Key words: breast cancer, macrophage migration inhibitory factor, CD74, cell proliferation, tumor microenvironment, HER2, treatment

\section{Contents}

1. Introduction

2. MIF and breast cancer: experimental studies

3. MIF and breast cancer: clinical studies

4. Conclusions and perspectives

\section{Introduction}

Breast cancer (BC) is the most frequently occurring malignant disease among women worldwide, accounting for nearly one fourth of the total new cancer cases (1). Despite marked progress in therapeutic strategies advanced $\mathrm{BC}$ remains a deadly disease, prompting efforts to advance our understanding of $\mathrm{BC}$ biology, with the aim of developing innovative approaches. Substantial research has been, and are conducted in the field of cross-talk between cancer cells and their microenvironment (2). Several tumor cell and stromal cell-derived factors have been identified and involved in these complex interactions, among them the macrophage migration inhibitory factor (MIF) (3). MIF is an evolutionarily highly conserved pleiotropic chemokine identified in 1966 by Bloom and Bennett as a protein secreted by $\mathrm{T}$ cells and inhibiting the migration of macrophages. Subsequently, it was shown that this chemokine is not only secreted by lymphocytes but also by other immune cells such as macrophages and non-immune cells such as endothelial and epithelial cells (4). In 1994, Paralkar and Wistow described the MIF gene, which is a small gene of $<1 \mathrm{~Kb}$, localized on chromosome 22. MIF is a protein of 115 amino acids, with a molecular weight of $12.5 \mathrm{kDa}$, in which the active form is a trimer (5). MIF has an enzymatic activity called tautomerase, situated within an $\mathrm{N}$-terminal proline (Pro1), which catalyzed the tautomerization of $p$-hydroxyphenylpyruvate and D-dopachrome. Although, highly conserved this enzymatic activity has no natural substrate identified and its contribution to MIF biological properties is uncertain (6). MIF is stored in the intracellular compartment and released upon stimulation via unconventional pathway, where the Golgi-associated protein p115 could be involved (7).

The discovery that MIF was released from corticotrophic pituitary cells and override the anti-inflammatory effects of corticoids suggested a pivotal role in inflammatory diseases. 
Its involvement was later described in sepsis, autoimmune diseases such as rheumatoid arthritis and systemic lupus erythematous. It plays a master role in regulating the complex formation of atherogenesis and is elevated in serum of patients with metabolic syndrome $(8,9)$. There is growing evidence that MIF is involved in carcinogenesis. MIF is often overexpressed in tissues and cancer cells. Indeed, Kindt et al (10) showed that MIF expression increased during the tumor progression of head and neck cancer but also in hepatocellular carcinoma (11), ovarian cancer $(12)$ and other malignancies $(13,14)$. Currently, there is a general consensus that MIF promotes tumor growth by several mechanisms by acting on the cancer cells themselves but also on the neighboring or even distant cancerous and non-cancerous cells. MIF interacts with its receptor, CD74 to induce the activation of several pathways such as MAPK and PI3K/Akt. This interaction plays a role in cell proliferation via CD44 as describe by Shi et al (15) in 2006. MIF could also interact with CXCR4 to promote cell migration (16). MIF inhibits induction of p53-dependent apoptosis, increases production of vascular endothelial growth factor (VEGF) and inhibits the antitumor immune response $(4,17)$. In colorectal cancer cell lines MIF modulates the expression of cyclooxygenase-2 (COX-2), an important contributor to carcinogenesis (18). In the $\mathrm{C} 4-2 \mathrm{~b}$ prostate cancer cell line, NS-398 a COX-2 inhibitor increases MIF expression by $\mathrm{NF}-\kappa \mathrm{B}$ transcription factor leading to a more aggressive cell differentiation (19). In esophageal squamous cell carcinoma, aspirin and NS-398 significantly inhibit MIF expression (20). Notably, elevated COX-2 expression in breast cancer is associated with a poor prognosis (21) and a meta-analysis of clinical studies suggests a slightly protective effect of COX-2 inhibitors against breast cancer (22). Finally, MIF modulates metastatic behavior of tumor cells and affects tumor stromal cells in a complex manner $(3,23,24)$.

Here, we review the clinical and experimental published data on MIF in breast cancer and discuss the potential clinical implications.

\section{MIF and breast cancer: experimental studies}

MIF and its receptor complex CD74/CD44 and CXCR4. In 2009, Verjans et al (25) studied the expression of MIF in invasive and non-invasive breast cancer cell lines. Non-invasive ductal breast cancer cell lines (MDA-MB-468 and ZR-75-1) showed an upregulation of MIF compared to benign epithelial breast cells (MCF-12A). Surprisingly, MIF was less expressed in invasive cells (MDA-MB-231). They observed no constitutive MIF release in non-cancerous MCF-12A cells contrary to the cancerous cell lines MDA-MB-468 and MDA-MB-231. They next studied the effect of exogenous rMIF on the secretion rate of endogenous MIF by cancerous and non-cancerous cells and showed an obvious upregulation, the most dramatic effect was seen in MDA-MB-231 cells, suggesting that MIF secretion could be influenced by auto- and paracrine MIF in the tumor microenvironment (25). The mechanisms of MIF overexpression are not well known, but Schulz et al (26) suggested that one of them could be the result of MIF protein stabilization by the tumor-activated HSP90 chaperone complex. Moreover, MIF gene has been shown to be upregulated by hypoxia in human breast cancer cells MCF-7 (27). However, Larsen et al (28) suggested that hypoxia MIF upregulation in MCF-7 is dependent on the cell genotype and that its secretion from hypoxic MCF-7 cells is regulated at the level of transcription independently of HIF. CD74, the main MIF receptor, is overexpressed, but not prominently, in invasive MDA-MB-231 cells, compared with non-cancerous MCF-12A cells (25). CXCR-4, the receptor of chemokine CXCL-12, can also bind to MIF. Indeed, JNK activation occurred when MIF interacts with CXCR-4 in Jurkat T cells (29). In breast cancer cell line, CXCR-4 expression is high in MDA-MB-231 aggressive cells and low in less aggressive MCF-7 cells (30). These in vitro data confirmed the involvement of the MIF complex in the carcinogenesis of breast cancer.

MIF promotes cell proliferation. Lue et al (31) showed on various breast cancer cell lines that the interaction of MIF with its membrane receptor CD74 induced activation of PI3K/Akt signaling pathway, promoting cell survival. They also found stronger MIF expression in breast cancer cell lines MCF-7 and ZR 75-1 compared to normal breast cell line MCF-12A but also in MDA-MB-468 cancer cells. They correlated MIF expression to Akt phosphorylation ratio and studied the response of these cell lines to exogenous rMIF. Breast cancer cells are unresponsive to exogenous rMIF when the Akt pathway is maximally activated or functionally blocked and when endogenous MIF is already high (31). Verjans et al (25) have also showed that recombinant MIF stimulates the proliferation of non-invasive and invasive cancer cell lines. Moreover, Simpson et al (32) demonstrated that the depletion of MIF has no impact on the growth of cancer cells in vitro. Lim et al (33) studied the regulation of MIF by epidermal growth factor receptor (EGFR) in the MCF10AT model of breast cancer progression. After EGF stimulation the level of MIF expression decreased in normal breast mammary epithelial cells but increased in MCF10AT1k preneoplastic and MCF10CA1h low-grade breast cancer cells and was unchanged in high grade cancer cells. Inversely, the silencing of MIF decreased EGF-stimulated CA1h cell proliferation. Further to these results, they proposed a proliferative pathway linking EGFR stimulating MEK and finally MIF (33).

\section{MIF and microenvironment modulation}

MIF as an immunomodulator. In the 4T1 murine model of breast cancer, Simpson et al (32) showed that MIF promotes tumor growth and metastasis by increasing the prevalence of a highly immune suppressive subpopulation of myeloid-derived suppressor cells (MDSCs) within the tumor. These results are in line with the study of Drews-Elger et al (34) demonstrating that, in pre-clinical models, the systemic recruitment of $\mathrm{S} 100 \mathrm{~A}^{+}$myeloid cells (including MDSCs) is promoted by MIF among others tumor-derived factors, S100A8 being a pro-inflammatory mediator secreted by MDSC. In vitro, MIF knockdown does not alter the migration ability and growth rate of MDA-MB-231 cells but, in vivo, depletion of MIF decreased primary tumor growth and metastatic burden in the lungs, correlated with a reduction of the number of $\mathrm{S} 100 \mathrm{~A} 8^{+}$ infiltrating cells. They suggested that MIF produced by the tumor promotes tumor progression by recruiting $\mathrm{S} 100 \mathrm{~A} 8^{+}$cells 


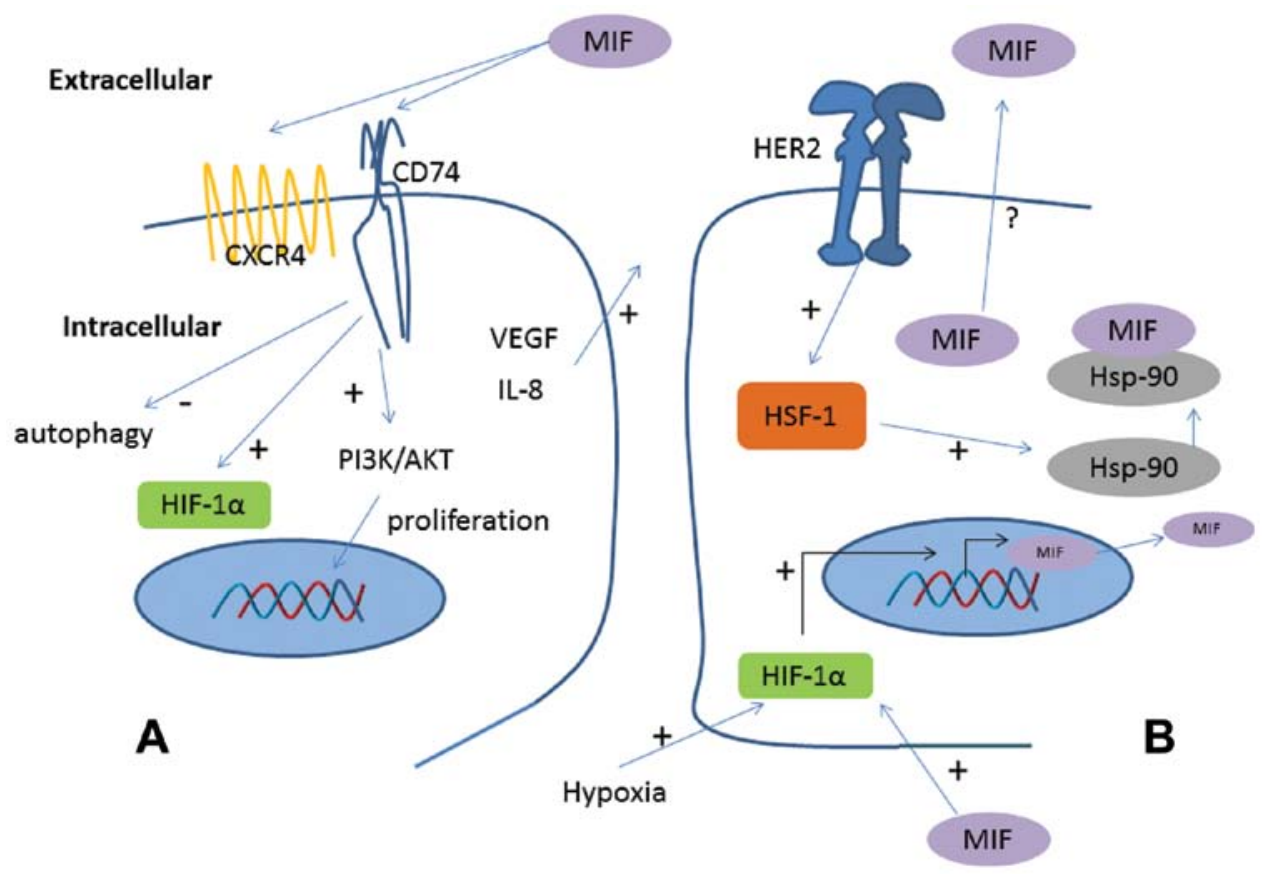

Figure 1. Schematic model of MIF pathways in breast cancer cells (BCC). (A) Auto- and paracrine MIF effects: MIF interacts with its main receptor CD74 and CXCR4, promoting cell survival by activation of PI3K/AKT signaling pathway, neo-angiogenesis by increased secretion levels of VEGF and IL-8 and inhibiting autophagy. (B) Regulation of MIF synthesis: MIF is upregulated in BCC by HIF-1 $\alpha$ and other potential hypoxia induced mechanisms, stabilized by Hsp-90 particularly in HER2 overexpressed BCC and secreted by unconventional pathway. In turn it enhances HIF-1 $\alpha$ activation.

acting as potent immunosuppressors and driving invasion, migration and angiogenesis (34).

MIF and neo-angiogenesis. In 2008, Xu et al (35) demonstrated not only that the MIF expression increased in cancerous cell lines compared to normal epithelial cells but also that addition of exogenous MIF in cell culture induced a dose-dependent increase in VEGF and IL-8 secretion, two factors implicated in angiogenesis. Other studies have showed that MIF was linked to hypoxia. Indeed, MCF-7 cells, under hypoxia condition, present an upregulation of MIF mRNA after 16 and $24 \mathrm{~h}$ compare to normoxic condition (28). The effect of MIF on HIF-1 activity was investigated in human breast cancer MCF-7 and MDA-MB-231 cells by Oda et al (36). They demonstrated that intracellular overexpression or extracellular administration of MIF enhances activation of HIF-1 under hypoxic conditions in MCF-7 cells, involving the CD74 receptor.

MIF and migration. Martinez et al (24) demonstrated in their study that peripheral blood plasma from breast cancer patients induced a higher transendothelial migration of MDA-MB-231 and MCF-7 cells than plasma from healthy volunteers. They also found significantly higher MDA-MB-231 cell proliferation. These results could be linked to the higher levels of MIF and others cytokines in peripheral blood plasma of breast cancer patients compared to the healthy volunteers.

MIF and autophagy. Autophagy is a process that maintains cellular homeostasis under stress conditions. The microtubuleassociated protein 1 light chain 3 (LC3-II) is proportional to the number of autophagic vacuole formation and its expression level can be used to quantify autophagy. In their study, $\mathrm{Wu}$ et al (37), demonstrated that the diminution of MIF expression by siRNA induce increase of LC3-II expression. In the same study, they showed that SRC-3 (steroid receptor coactivator 3), an oncogene that favors drug resistance in cancer, targets MIF. Indeed, knockdown of SRC-3 in MCF-7 cells induces a decrease of MIF expression. This was reversed by exogenous recombinant MIF. They suggested that MIF could inhibit autophagy in breast cancer cells.

MIF and HER2. In ErbB2 transgenic model of human HER2positive breast cancer mice, Schultz et al (38) demonstrated that genetic MIF deletion protected from the development of breast cancer and led to extended survival, suggesting a link between HER2 status and MIF. ErbB2 cancers in $\mathrm{MIF}^{+/+}$mice showed overexpression of MIF in malignant breast epithelium. Delayed tumor progression in $\mathrm{MIF}^{-/}$ErbB2 mice seemed to be linked to slower tumor growth with decreased proliferation as showed by lower $\mathrm{Ki}-67$ staining. They later showed that specific inhibition of HER2 signaling in HER2 overexpressing breast cancer cells reduces MIF levels by abolishing its stabilization. Indeed, overexpressed HER2 activates HSF1 (heat-shock factor1), transcriptional regulator of HSP90 which stabilizes MIF (26).

MIF and drug resistance. Wu et al (37) showed that autophagic cell death induced by MIF knockdown increased the chemosensitivity of breast cancer cells to doxorubicin, apoptosis being not affected. The aza derivatives of resveratrol, a natural phytoalexin, showed anti-proliferative effect in the MCF-7 cell line and inhibits the MIF tautomerase activity (39). It was also shown to reverse partially the paclitaxel resistance in MDA-MB-231/PacR cell lines (40).

Based on these data, we suggest a schematic model of MIF involvement in breast cancer cells (Fig. 1). 
Table I. MIF tumor tissue expression level and histoprognostic factors.

\begin{tabular}{|c|c|c|c|c|c|c|c|c|}
\hline Réfs. & $\begin{array}{l}\text { No. of } \\
\text { patients }\end{array}$ & $\begin{array}{l}\text { Tumor } \\
\text { size }\end{array}$ & $\begin{array}{c}\text { Lymph } \\
\text { node status }\end{array}$ & $\begin{array}{l}\text { Histological } \\
\text { grade }\end{array}$ & $\begin{array}{c}\mathrm{PR} / \mathrm{ER} \\
\text { expression }\end{array}$ & $\begin{array}{l}\text { HER2 } \\
\text { status }\end{array}$ & $\begin{array}{l}\text { TRN } \\
\text { status }\end{array}$ & $\begin{array}{r}\text { Ki-67 } \\
\text { level }\end{array}$ \\
\hline Bando et al (41) & 93 & NS & $\begin{array}{c}0.039 \\
\text { (inverse) }\end{array}$ & - & NS & - & - & - \\
\hline Xu et al (35) & 121 & NS & 0.063 & NS & - & 0.03 & - & - \\
\hline Verjans et al (25) & 175 & $\begin{array}{c}0.007 \\
\text { (inverse) }\end{array}$ & NS & NS & $\begin{array}{l}0.006 \\
0.028\end{array}$ & - & - & - \\
\hline Choi et al (46) & 276 & NS & NS & NS & NS & $<0.001$ & - & - \\
\hline Richard et al (42) & 96 & $\begin{array}{c}0.02^{\mathrm{a}} \\
\text { (inverse) }\end{array}$ & NS & NS & NS & NS & NS & NS \\
\hline
\end{tabular}

PR, progesterone receptor; OR, estrogen receptor; TRN status, triple receptor negative status; NS, non-significant; - , non available; ${ }^{2}$ Stromal compartment.

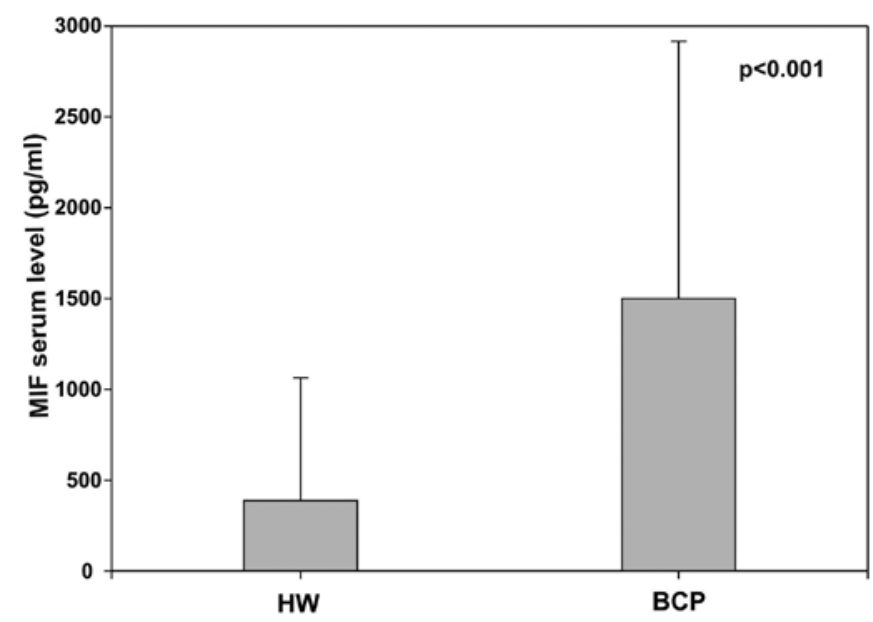

Figure 2. Serum level of MIF is increased in BCP compared to HW (MannWhitney test, $\mathrm{P}<0.001)$.

\section{MIF and breast cancer: clinical studies}

MIF serum levels in human breast cancer patients. Five studies evaluated MIF serum levels in breast cancer patients (BCP) compared to healthy volunteers (HV): all showed significant increased levels in BCP $(24,35,41-43)$. Our data are showed in Fig. 2 (42). Using a set of serum proteins, two others studies found a non-diagnostic MIF serum elevation in BCP $(44,45)$. Correlations with invasive tumor characteristics and patients prognostic are poorly documented: Bando et al (27) found no significant correlation with MIF intratumoral levels and clinico-pathological factors but a significant inverse correlation with nodal status. In the study of Fersching et al (43) pre-therapeutic levels of MIF tended to be higher in nonresponsive patients undergoing preoperative chemotherapy. No data are available concerning MIF serum levels and tumor recurrence. These sets of data suggest that the increased serum level of MIF in BCP could be a non-specific signature of a systemic response to breast cancer.
MIF and CD74 expression in breast cancer tissue. MIF expression in breast cancer tissue has been evaluated in five studies, using immunohistochemical techniques in four, with different scoring scales, and western blot analysis and RT-PCR in one $(25,35,41,42,46)$. All found a high level of MIF expression in the tumor tissue. Xu et al (35) showed higher microvessels density in tumors with higher MIF expression. Correlations with classical tumor characteristics are elusive (Table I). MIF expression level was evaluated in glandular compartment only except in our study where we have evaluated stromal and glandular compartments separately. Bando et al (41) found an inverse correlation with nodal involvement, Verjans et al (25) a positive correlation with progesterone and estrogen receptor expression. A negative correlation between MIF expression and tumor size was shown by Verjans. MIF expression significantly correlated with HER-2 for Xu et al (35). Choi et al (46) confirmed this result in a study evaluating the expression of a set of proteins in invasive breast cancer. These observations could be put in perspective with the experimental data describe earlier (MIF and HER2).

Our study is the only one evaluating the expression of MIF and its receptor CD74 on the same breast cancer biopsies and normal breast tissue (42). MIF tissue expression, quantified by a modified Allred score, was strongly increased in carcinoma compared to tumor-free specimens, in the cancer cells and in the peritumoral stroma, with fibroblasts the most intensely stained (Fig. 3). We did not find any significant correlation with histoprognostic factors, except for a significant inverse correlation between tumor size and MIF stromal positivity. These findings have to be put in perspective with the hypothesis that MIF could modulate the tumor size by inhibiting recruitment of cancer-associated fibroblasts (CAFs)/myofibroblasts (23) and several recent publications underscoring the pivotal role of CAFs in tumor progression $(3,47,48,49)$. CD74 staining was heterogeneous and significantly decreased in cancer cells but increased in the surrounding stroma, namely in lymphocytes, macrophages and vessel endothelium. There was no significant variation according to classical histoprognostic factors, except that CD74 stromal expression was significantly correlated 

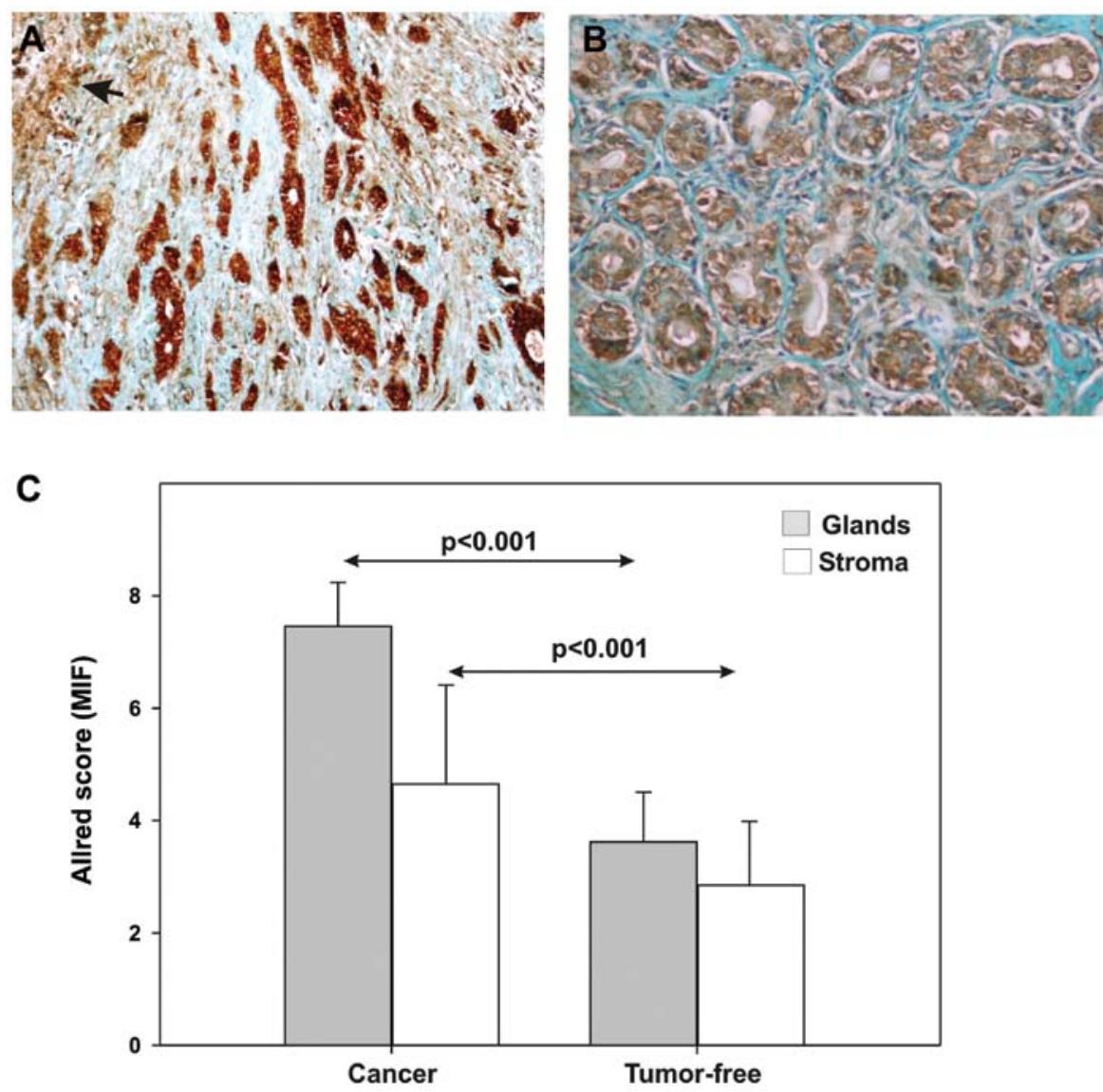

Figure 3. Immunohistochemical detection of MIF in non-cancerous breast (B) and breast cancer tissue sections with a strong positivity in the peritumoral fibroblasts (arrow) (A). Semi-quantitative analysis (Allred score) of MIF expression in glandular and stromal compartments (C) (Mann-Whitney test, $\mathrm{P}<0.001)$.

with triple-negative receptor (TRN) status and the absence of estrogen receptors (42). This finding could be compared with the growing importance of evaluating stromal lymphocytes infiltration of the TRN tumor (50).

Only Xu et al (25) and Verjans et al (35) have reported data concerning MIF expression levels and patients prognosis. The results are discordant with positive MIF expression correlating with worse disease-free survival for $\mathrm{Xu}$ et al, but a better overall and recurrence-free survival for Verjans et al. However, MIF scoring scales and cut-off for positivity were not the same. These data show an increased expression of MIF in breast cancer tissue and suggest that this cytokine contribute to shape and modulate the tumor aggressivity.

We did not find any published data concerning MIF and CD74 expression in non-invasive breast cancer tissue.

\section{Conclusions and perspectives}

MIF is a pleiotropic chemokine involved in carcinogenesis. Experimental and clinical studies suggest that MIF could have a multi-functional role in human breast cancer. Firstly, MIF has auto- and paracrine effects on cancer cells promoting proliferation, migration and inhibiting autophagy and apoptosis. Secondly, MIF contributes to shape the immune and non-immune tumor microenvironment leading to immunomodulation and angiogenesis promoting cancer cells growth, invasion and metastases. Thirdly, MIF acts systemically leading to metabolic disturbances such as metabolic syndrome and negative immune implications promoting tumor growth and metastases development. Even if many questions remain unresolved regarding the mechanisms of cell modulation by MIF inside the primary or metastatic tumor, therapeutic targeting of this cytokine could provide clinical benefits. Several experimental data have been published exploring MIF pathway inhibition. HSP90 stabilizes MIF and its pharmacologic inhibition by $17-\mathrm{N}$-allylamino17-demethoxygeldanamycin (17-AAG, Tanespimycin) or suberoylanilide-hydroxamic-acid (SAHA, vorinostat) destabilizes MIF protein leading to death of human breast cancer cells lines. This is reversed by excess ectopic MIF. In an ErbB2 transgenic model of human HER2-positive breast cancer, systemic administration of $17 \mathrm{AAG}$ reduces MIF expression and inhibits growth of MIF-expressing, but not MIF-deficient tumors (40). Ganetespib, an HSP90 inhibitor has been recently tested with success in metastatic HER2 breast cancer in combination with paclitaxel (51). Part of the activity of these molecules could be linked to MIF inactivation. Human anti-MIF antibodies, low molecular weight inhibitors of the tautomerase activity of MIF protein, blocking agents of MIF receptors have been tested in diverse human cancer cell lines with some positive results but we did not find any specific breast cancer data. A phase I trial with antiMIF antibody is being tested in advanced solid tumor (52). Anti-CD74 strategy with milatuzumab has been success- 
fully investigated in hematologic malignancies (53). MIF being a potent endogenous mediator of COX-2 expression and this enzyme being linked to breast cancer progression, anti COX-2 molecules could be tested as indirect anti-MIF strategies $(21,54)$. Using a highly metastatic syngenic murine C3L5 breast cancer model, Majunder et al (55) showed that indomethacin, a COX-1/COX-2 inhibitor inhibited cell proliferation and migration. In vitro, celecoxib, a COX-2 inhibitor reduced tumor growth and spontaneous lung and lymph node metastases. However published data on the impact of COX-2 inhibition on MIF expression and its biological consequences are lacking in breast cancer cells.

In conclusions, MIF pathway is obviously involved in the breast cancer biology and interfering with it remains an attractive but complex challenge.

\section{Acknowledgements}

N.K. is the recipient of a grant (Televie) from the National Fund for Scientific Research.

\section{References}

1. Jemal A, Bray F, Center MM, Ferlay J, Ward E and Forman D: Global cancer statistics. CA Cancer J Clin 61: 69-90, 2011.

2. Pietras K and Östman A: Hallmarks of cancer: Interactions with the tumor stroma. Exp Cell Res 316: 1324-1331, 2010.

3. Mitchell RA and Yaddanapudi K: Stromal-dependent tumor promotion by MIF family members. Cell Signal 26: 2969-2978, 2014.

4. Conroy H, Mawhinney L and Donnelly SC: Inflammation and cancer: Macrophage migration inhibitory factor (MIF) - the potential missing link. QJM 103: 831-836, 2010.

5. Donn RP and Ray DW: Macrophage migration inhibitory factor: Molecular, cellular and genetic aspects of a key neuroendocrine molecule. J Endocrinol 182: 1-9, 2004.

6. Swope M, Sun HW, Blake PR and Lolis E: Direct link between cytokine activity and a catalytic site for macrophage migration inhibitory factor. EMBO J 17: 3534-3541, 1998.

7. Li XJ, Luo Y and Yi YF: P115 promotes growth of gastric cancer through interaction with macrophage migration inhibitory factor. World J Gastroenterol 19: 8619-8629, 2013.

8. Zernecke A, Bernhagen J and Weber C: Macrophage migration inhibitory factor in cardiovascular disease. Circulation 117: 1594-1602, 2008.

9. Kim H, Lee S, Kim HJ, Kong MH, Kim YR, Kang SH, Lee K, Leng L, Lee B, Park CG, et al: Elevated levels of macrophage migration inhibitory factor in women with metabolic syndrome. Horm Metab Res 43: 642-645, 2011.

10. Kindt N, Preillon J, Kaltner H, Gabius HJ, Chevalier D, Rodriguez A, Johnson BD, Megalizzi V, Decaestecker C, Laurent $\mathrm{G}$, et al: Macrophage migration inhibitory factor in head and neck squamous cell carcinoma: Clinical and experimental studies. J Cancer Res Clin Oncol 139: 727-737, 2013.

11. Wang D, Luo L, Chen W, Chen LZ, Zeng WT, Li W and Huang XH: Significance of the vascular endothelial growth factor and the macrophage migration inhibitory factor in the progression of hepatocellular carcinoma. Oncol Rep 31: 1199-1204, 2014.

12. Krockenberger M, Kranke P, Häusler S, Engel JB, Horn E, Nürnberger K, Wischhusen J, Dietl J and Hönig A: Macrophage migration-inhibitory factor levels in serum of patients with ovarian cancer correlates with poor prognosis. Anticancer Res 32: 5233-5238, 2012.

13. Tan L, Ye X, Zhou Y, Yu M, Fu Z, Chen R, Zhuang B, Zeng B, Ye $\mathrm{H}$, Gao W, et al: Macrophage migration inhibitory factor is overexpressed in pancreatic cancer tissues and impairs insulin secretion function of $\beta$-cell. J Transl Med 12: 92, 2014.
14. He XX, Yang J, Ding YW, Liu W, Shen QY and Xia HH: Increased epithelial and serum expression of macrophage migration inhibitory factor (MIF) in gastric cancer: Potential role of MIF in gastric carcinogenesis. Gut 55: 797-802, 2006.

15. Shi X, Leng L, Wang T, Wang W, Du X, Li J, McDonald C, Chen Z, Murphy JW, Lolis E, et al: CD44 is the signaling component of the macrophage migration inhibitory factor-CD74 receptor complex. Immunity 25: 595-606, 2006.

16. Lee CY, Su MJ, Huang CY, Chen MY, Hsu HC, Lin CY and Tang CH: Macrophage migration inhibitory factor increases cell motility and up-regulates $\alpha v \beta 3$ integrin in human chondrosarcoma cells. J Cell Biochem 113: 1590-1598, 2012.

17. Mitchell RA: Mechanisms and effectors of MIF-dependent promotion of tumourigenesis. Cell Signal 16: 13-19, 2004.

18. Xin D, Rendon BE, Zhao M, Winner M, McGhee Coleman A and Mitchell RA: The MIF homologue D-dopachrome tautomerase promotes COX-2 expression through $\beta$-catenin-dependent and -independent mechanisms. Mol Cancer Res 8: 1601-1609, 2010.

19. Meyer-Siegler K: COX-2 specific inhibitor, NS-398, increases macrophage migration inhibitory factor expression and induces neuroendocrine differentiation in $\mathrm{C} 4-2 \mathrm{~b}$ prostate cancer cells. Mol Med 7: 850-860, 2001.

20. Xia HH, Zhang ST, Lam SK, Lin MC, Kung HF and Wong BC: Expression of macrophage migration inhibitory factor in esophageal squamous cell carcinoma and effects of bile acids and NSAIDs. Carcinogenesis 26: 11-15, 2005.

21. Ristimäki A, Sivula A, Lundin J, Lundin M, Salminen T, Haglund C, Joensuu $\mathrm{H}$ and Isola J: Prognostic significance of elevated cyclooxygenase-2 expression in breast cancer. Cancer Res 62: 632-635, 2002.

22. de Pedro M, Baeza S, Escudero MT, Dierssen-Sotos T, GómezAcebo I, Pollán M and Llorca J: Effect of COX-2 inhibitors and other non-steroidal inflammatory drugs on breast cancer risk: A meta-analysis. Breast Cancer Res Treat 149: 525-536, 2015.

23. Tarnowski M, Grymula K, Liu R, Tarnowska J, Drukala J, Ratajczak J, Mitchell RA, Ratajczak MS and Kucia M: Human Rhabdomyosarcomas secrete MIF that modulates metastatic behavior of tumor cells and inhibits recruitment of cancer associated fibroblasts. Mol Cancer Res 8: 1328-1343, 2010.

24. Martinez LM, Vallone VBF, Labovsky V, Choi H, Hofer EL, Feldman L, Bordenave RH, Batagelj E, Dimase F, Villafañe AR, et al: Changes in the peripheral blood and bone marrow from untreated advanced breast cancer patients that are associated with the establishment of bone metastases. Clin Exp Metastasis 31: 213-232, 2014.

25. Verjans E, Noetzel E, Bektas N, Schûtz AK, Lue H, Lennartz B, Hartmann A, Dahl E and Bernhagen J: Dual role of macrophage migration inhibitory factor (MIF) in human breast cancer. BMC Cancer 9: 230, 2009.

26. Schulz R, Streller F, Scheel AH, Rüschoff J, Reinert MC, Dobbelstein M, Marchenko ND and Moll UM: HER2/ErbB2 activates HSF1 and thereby controls HSP90 clients including MIF in HER2-overexpressing breast cancer. Cell Death Dis 5: e980, 2014.

27. Bando H, Toi M, Kitada $\mathrm{K}$ and Koike M: Genes commonly upregulated by hypoxia in human breast cancer cells MCF-7 and MDA-MB-231. Biomed Pharmacother 57: 333-340, 2003.

28. Larsen M, Tazzyman S, Lund EL, Junker N, Lewis CE, Kristjansen PE and Murdoch C: Hypoxia-induced secretion of macrophage migration-inhibitory factor from MCF-7 breast cancer cells is regulated in a hypoxia-inducible factor-independent manner. Cancer Lett 265: 239-249, 2008.

29. Lue H, Dewor M, Leng L, Bucala R and Bernhagen J: Activation of the JNK signalling pathway by macrophage migration inhibitory factor (MIF) and dependence on CXCR4 and CD74. Cell Signal 23: 135-144, 2011.

30. Dewan MZ, Ahmed S, Iwasaki Y, Ohba K, Toi M and Yamamoto N: Stromal cell-derived factor-1 and CXCR4 receptor interaction in tumor growth and metastasis of breast cancer. Biomed Pharmacother 60: 273-276, 2006.

31. Lue H, Thiele M, Franz J, Dahl E, Speckgens S, Leng L, FingerleRowson G, Bucala R, Lüscher B and Bernhagen J: Macrophage migration inhibitory factor (MIF) promotes cell survival by activation of the Akt pathway and role for CSN5/JAB1 in the control of autocrine MIF activity. Oncogene 26: 5046-5059, 2007.

32. Simpson KD, Templeton DJ and Cross JV: Macrophage migration inhibitory factor promotes tumor growth and metastasis by inducing myeloid-derived suppressor cells in the tumor microenvironment. J Immunol 189: 5533-5540, 2012. 
33. Lim S, Choong LY, Kuan CP, Yunhao C and Lim YP: Regulation of macrophage inhibitory factor (MIF) by epidermal growth factor receptor (EGFR) in the MCF10AT model of breast cancer progression. J Proteome Res 8: 4062-4076, 2009.

34. Drews-Elger K, Iorns E, Dias A, Miller P, Ward TM, Dean S, Clarke J, Campion-Flora A, Rodrigues DN, Reis-Filho JS, et al: Infiltrating $\mathrm{S} 100 \mathrm{~A} 8^{+}$myeloid cells promote metastatic spread of human breast cancer and predict poor clinical outcome. Breast Cancer Res Treat 148: 41-59, 2014.

35. Xu X, Wang B, Ye C, Yao C, Lin Y, Huang X, Zhang Y and Wang S: Overexpression of macrophage migration inhibitory factor induces angiogenesis in human breast cancer. Cancer Lett 261: 147-157, 2008.

36. Oda S, Oda T, Nishi K, Takabuchi S, Wakamatsu T, Tanaka T, Adachi T, Fukuda K, Semenza GL and Hirota K: Macrophage migration inhibitory factor activates hypoxia-inducible factor in a p53-dependent manner. PLoS One 3: e2215, 2008.

37. Wu MY, Fu J, Xu J, O'Malley BWO and Wu RC: Steroid receptor coactivator 3 regulates autophagy in breast cancer cells through macrophage migration inhibitory factor. Cell Res 22: 1003-1021, 2012.

38. Schulz R, Marchenko ND, Holembowski L, Fingerle-Rowson G, Pesic M, Zender L, Dobbelstein M and Moll UM: Inhibiting the HSP90 chaperone destabilizes macrophage migration inhibitory factor and thereby inhibits breast tumor progression. J Exp Med 209: 275-289, 2012

39. Fujita Y, Islam R, Sakai K, Kaneda H, Kudo K, Tamura D, Aomatsu K, Nagai T, Kimura $\mathrm{H}$, Matsumoto $\mathrm{K}$, et al: Aza-derivatives of resveratrol are potent macrophage migration inhibitory factor inhibitors. Invest New Drugs 30: 1878-1886, 2012.

40. Sprouse AA and Herbert BS: Resveratrol augments paclitaxe treatment in MDA-MB-231 and paclitaxel-resistant MDA-MB231 breast cancer cells. Anticancer Res 34: 5363-5374, 2014.

41. Bando H, Matsumoto G, Bando M, Muta M, Ogawa T, Funata N, Nishihira J, Koike $M$ and Toi M: Expression of macrophage migration inhibitory factor in human breast cancer: Association with nodal spread. Jpn J Cancer Res 93: 389-396, 2002.

42. Richard V, Kindt N, Decaestecker C, Gabius HJ, Laurent G, Noël JC and Saussez S: Involvement of macrophage migration inhibitory factor and its receptor (CD74) in human breast cancer. Oncol Rep 32: 523-529, 2014

43. Fersching DM, Nagel D, Siegele B, Salat C, Heinemann V, Holdenrieder S and Stoetzer OJ: Apoptosis-related biomarkers sFAS, MIF, ICAM-1 and PAI-1 in serum of breast cancer patients undergoing neoadjuvant chemotherapy. Anticancer Res 32: 2047-2058, 2012.

44. Jesneck JL, Mukherjee S, Yurkovetsky Z, Clyde M, Marks JR, Lokshin AE and Lo JY: Do serum biomarkers really measure breast cancer? BMC Cancer 9: 164, 2009.
45. Opstal-van Winden AW, Rodenburg W, Pennings JLA, van Oostrom CTM, Beijnen JH, Peeters PHM, van Gils CH and de Vries A: A bead-based multiplexed immunoassay to evaluate breast cancer biomarkers for early detection in pre-diagnostic serum. Int J Mol Sci 13: 13587-13604, 2012.

46. Choi J, Jung WH and Koo JS: Metabolism-related proteins are differentially expressed according to the molecular subtype of invasive breast cancer defined by surrogate immunohistochemistry. Pathobiology 80: 41-52, 2013.

47. Catteau X, Simon P, Vanhaeverbeek M and Noël JC: Variable stromal periductular expression of CD34 and smooth muscle actin (SMA) in intraductal carcinoma of the breast. PLoS One 8: e57773, 2013

48. Catteau X, Simon P and Noël JC: Myofibroblastic stromal reaction and lymph node status in invasive breast carcinoma: possible role of the TGF- $\beta 1 /$ TGF- $\beta$ R 1 pathway. BMC Cancer 4 : 499, 2014

49. Catteau X, Simon P and Noël JC: Myofibroblastic reaction is a common event in metastatic disease of breast carcinoma: A descriptive study. Diagn Pathol 9: 196, 2014.

50. Salgado R, Denkert C, Demaria S, Sirtaine N, Klauschen F, Pruneri G, Wienert S, Van den Eynden G, Baehner FL, PenaultLlorca F, et al: The evaluation of tumor-infiltrating lymphocytes (TILs) in breast cancer: Recommendations by an International TILs Working Group 2014. Ann Oncol 26: 259-271, 2015.

51. Jhaveri K, Chandarlapaty S, Lake D, Gilewski T, Robson M, Goldfarb S, Drullinsky P, Sugarman S, Wasserheit-Leiblich C, Fasano J, et al: A phase II open-label study of ganetespib, a novel heat shock protein 90 inhibitor for patients with metastatic breast cancer. Clin Breast Cancer 14: 154-160, 2014.

52. Baxalta US Inc. (sponsor): Phase I Study of anti-Macrophage Migration Inhibitory Factor antibody in solid Tumors. ClinicalTrials.gov identifier: NCT01765790. https://clinicaltrials. gov/ct2/show/NCT01765790.

53. Berkova Z, Tao RH and Samaniego F: Milatuzumab - a promising new immunotherapeutic agent. Expert Opin Investig Drugs 19: 141-149, 2010.

54. Howe LR: Inflammation and breast cancer. Cyclooxygenase/ prostaglandin signaling and breast cancer. Breast Cancer Res 9: $210,2007$.

55. Majumder M, Xin X, Liu L, Girish GV and Lala PK: Prostaglandin E2 receptor EP4 as the common target on cancer cells and macrophages to abolish angiogenesis, lymphangiogenesis, metastasis, and stem-like cell functions. Cancer Sci 105: $1142-1151,2014$ 